\title{
OS DESAFIOS DE UMA PROPOSTA DE AVALIAÇÃO EM VALORES PARA O PROGRAMA "A UNIÃO FAZ A VIDA": UM ESTUDO PILOTO
}

MARIALVA ROSSI TAVARES

\section{RESUMO}

O artigo aborda um estudo piloto cujo objetivo é a construção de um instrumento para a avaliação de valores em uma dimensão quantitativa. Este estudo foi elaborado pela Fundação Carlos Chagas para o Programa "A União Faz a Vida", mantido pela Fundação Sicredi. Para maior compreensão do leitor, este artigo descreve resumidamente: o programa e seus princípios (valores de cooperação e cidadania); a proposta da avaliação envolvendo sua abrangência, a metodologia de construção da escala e sua interpretação com os resultados obtidos. Trata-se de um estudo que tem por finalidade oferecer insumos aos responsáveis pelos sistemas de ensino quanto à formação cidadã de nossas crianças.

PALAVRAS-CHAVE: ESCALA DE AVALIAÇÃO • AVALIAÇÃO DO PROGRAMA • VALORES - CIDADANIA. 


\title{
RESUMEN
}

El artículo aborda un estudio piloto cuyo objetivo es la construcción de un instrumento para la evaluación de valores en una dimensión cuantitativa. Este estudio fue elaborado por la Fundación Carlos Chagas para el programa "La unión hace la vida", subvencionado por la Fundación Sicredi. Para una mayor comprensión del lector, este artículo describe resumidamente: el programa y sus principios (valores de cooperación y ciudadanía); la propuesta de la evaluación implicando sus alcances, la metodología de construcción de la escala y su interpretación con los resultados obtenidos. Se trata de un estudio que tiene por finalidad ofrecer insumos a los responsables de los sistemas de enseñanza en lo que se refiere a la formación ciudadana de nuestros niños.

PALABRAS CLAVE: ESCALA DE EVALUACIÓN • EVALUACIÓN DEL PROGRAMA • VALORES • CIUDADANÍA.

\begin{abstract}
This article discusses a pilot study whose goal is to build an instrument for the assessment of values on a quantitative dimension. This study was prepared by the Carlos Chagas Foundation for the program "Union Makes Life", maintained by the Sicredi Foundation. For a better understanding by the reader, this article briefly describes the program and its principles (values of cooperation and citizenship), the assessment proposal involving its scope, the methodology used to construct the scale and the interpretation of the results obtained. It is a study that aims to provide input to those responsible for the education systems concerning the civic education of our children.
\end{abstract}

KEYWORDS: SCALE OF ASSESSMENT • PROGRAM

EVALUATION • VALUES • CITIZENSHIP. 


\section{INTRODUÇÃO}

Este artigo relata a experiência da Fundação Carlos Chagas na tentativa de construir um projeto de avaliação em valores para o Programa “A União Faz a Vida”, desenvolvido pela Fundação

1 A Fundação Sicredi é ligada ao Banco Cooperativo Sicredi e tem como objetivo estruturar, desenvolver e coordenar programas de educação que promovam cooperativismo de crédito e a formação de associados.
Sicredi ${ }^{1}$. Trata-se de uma descrição dos esforços para iniciar a construção de uma escala de valores, de acordo com os princípios do programa, com o propósito de se estabelecer parâmetros e indicadores de avaliação do mesmo.

\section{O PROGRAMA "A UNIÃO FAZ A VIDA" E SEUS PRESSUPOSTOS}

O propósito da Fundação Sicredi foi desenvolver uma proposta de educação cooperativa, procurando criar uma metodologia que privilegiasse o empreendedorismo e o coletivismo, em substituição às práticas individuais predominantes nas escolas de Ensino Fundamental. Nessa perspectiva, a criação do Programa “A União Faz a Vida” teve como objetivo principal "Construir e vivenciar atitudes e valores de cooperação 
e cidadania, por meio de práticas de educação cooperativa, contribuindo para a educação integral de crianças e adolescentes, em âmbito nacional."

A ênfase na cooperação busca incorporar, ao cotidiano das crianças e adolescentes nas escolas, atitudes em prol de melhor convivência. Ao incentivar a cooperação, o diálogo, o comportamento solidário, tendo como meta um esforço abrangente para alcançar a comunidade, o programa visa colaborar para fortalecer a formação de uma consciência coletiva, que tem a cidadania como o valor básico a ser alcançado por uma sociedade democrática, cujos membros possam exercer plenamente seus direitos e responsabilidades. Neste sentido o programa enfatiza, dentre outros princípios, a noção de igualdade e responsabilidade.

O exercício da igualdade, segundo o programa, inclui o respeito, a diversidade e a equidade perante as leis. O respeito à diversidade está em reconhecer que as pessoas são diferentes e que todas devem ser tratadas como equivalentes, ou seja, a dignidade deve ser comum a todos por direito, pelo reconhecimento da sua diversidade e pelo respeito ético, uma vez que somos iguais e diferentes, e que essa ideia não é contraditória. A noção de equidade perante as leis traz implícita a ideia de que todos os indivíduos são submetidos à lei e gozam dos mesmos direitos e responsabilidades. A equidade não se efetiva pela simples aplicação de regras de direitos para todos, mas por meio de ações específicas que consideram a peculiaridade de pessoas, grupos e regiões.

Finalmente, a responsabilidade é uma obrigação de todos os cidadãos, no sentido de poder participar de decisões que afetam sua vida, e de assumir responsabilidade dos seus compromissos frente à sociedade. A identificação das necessidades, dos caminhos e ações precisa acontecer com o envolvimento de todos os sujeitos. Significa assumir um compromisso consigo e com os outros em torno de um objetivo.

A metodologia do Programa "A União Faz a Vida" estimula a perspectiva do trabalho com projetos, por meio da qual, educadores, crianças, adolescentes e comunidades vivem experiências colaborativas de aprendizagem. Essa metodologia prioriza o diálogo, a troca de saberes, a expressão de dúvidas, a resolução de conflitos, a percepção das diferenças. A metodologia 
de projetos constitui-se em elemento chave no processo de apropriação e expansão de conceitos, atitudes, valores e competências pessoais e sociais.

A implantação do programa prevê um treinamento aos professores que aderirem à ideia e um acompanhamento posterior para apoiá-los em sala de aula, nas ações específicas do trabalho com a metodologia.

\section{A PROPOSTA DE AVALIAÇÃo}

O projeto de avaliação teve como propósito oferecer aos responsáveis pelo programa uma visão de seu desenvolvimento e apresentou os seguintes objetivos:

- Avaliar a posição do público (crianças, jovens e professores) em relação a situações que envolvam as atitudes e os valores voltados para os conceitos de cooperação e cidadania.

- Avaliar a qualidade dos trabalhos desenvolvidos pelo programa, por meio de questionários destinados aos educadores, diretores das escolas envolvidas e demais agentes.

- Acompanhar e monitorar as atividades do programa quanto ao desenvolvimento de valores e atitudes de cooperação e cidadania.

Dados tais objetivos, a Fundação Carlos Chagas assumiu como ponto de partida iniciar o processo de construção de uma escala em valores que pudesse cobrir os aspectos valorativos mais importantes do programa e fosse útil na construção de parâmetros avaliativos para o programa ao longo do tempo.

A avaliação do Programa "A União Faz a Vida" foi realizada nos estados do Rio Grande do Sul, Paraná e Mato Grosso, envolvendo 61 Cooperativas/Sicredi e 140 municípios, segundo os dados informados em 2009, perfazendo 1.154 escolas, 13.703 educadores e 165.538 alunos. Foi prevista a elaboração de um processo de amostragem para selecionar os alunos a serem avaliados em cada município.

O processo de amostragem selecionou o número de alunos por município, procurando manter a proporção em 
que eles aparecem em relação ao total de alunos no estado e no programa.

TABELA 1 - Amostra prevista e real dos alunos e educadores envolvidos no programa

\begin{tabular}{|c|c|c|c|c|c|c|c|c|}
\hline \multirow[b]{2}{*}{ AMOSTRA } & \multicolumn{2}{|c|}{$\begin{array}{l}\text { RIO GRANDE } \\
\text { DO SUL }\end{array}$} & \multicolumn{2}{|c|}{ PARANÁ } & \multicolumn{2}{|c|}{ MATO GROSSO } & \multicolumn{2}{|c|}{ TOTAL } \\
\hline & PREVISTO & REAL & PREVISTO & REAL & PREVISTO & REAL & PREVISTO & REAL \\
\hline Alunos & 18.900 & 17.725 & 2.660 & 2.792 & 2.600 & 2.369 & 24.160 & 22.886 \\
\hline Educadores & 945 & 877 & 133 & 135 & 130 & 104 & 1.208 & 1.116 \\
\hline
\end{tabular}

Pela tabela 1, podemos perceber um bom retorno dos dados: o total de respostas à pesquisa atingiu $95 \%$ dos alunos previstos (22.886) e 92\% dos educadores (1.116). No estado do Rio Grande do Sul, tivemos a participação de $94 \%$ de alunos (17.725) e $93 \%$ de educadores (877). Este bom resultado de retorno, do ponto de vista da pesquisa, pode ser atribuído à forma como esses foram coletados, ou seja, por meio de questionários aplicados por pessoal treinado, que se deslocou até as escolas e seguiu os horários por elas disponibilizados. Os dados da tabela 1 permitem também verificar que, no estado do Paraná, houve um acréscimo de alunos e educadores em função da inclusão de alguns municípios.

Apesar dos diferentes objetivos, esse artigo tem como foco apenas os cuidados e procedimentos para a elaboração da escala de valores, considerando que o ano de 2010 constituiu o início do processo da construção da escala.

\section{A CONSTRUÇÃO DA ESCALA DE VALORES}

A elaboração de uma escala de avaliação sobre valores pressupõe sempre a identificação do que deve ser considerado como característico nas manifestações dos indivíduos que passam por um processo de intervenção (Programa). Assim, para esta fase foi planejada uma atividade conjunta com o grupo de assessores pedagógicos e coordenadores do programa vinculados ao Sicredi. Nessa atividade foram coletados dados que permitiram elaborar um quadro de especificação com os pontos considerados 
fundamentais e prioritários neste processo inicial de avaliação. Os valores identificados nesta atividade são apresentados no quadro a seguir e serviram de referência para a elaboração das questões e/ou itens que comporiam o instrumento de coleta de dados.

\section{QUADRO 1 - Matriz para elaboração dos itens}

\begin{tabular}{|c|c|c|}
\hline Área & Conteúdo & Descritores \\
\hline \multirow{7}{*}{ Cooperação } & \multirow{3}{*}{$\begin{array}{l}\text { Diálogo: Busca verificar a } \\
\text { capacidade de se afirmar, } \\
\text { de convencer o outro, mas } \\
\text { também de escutar, ouvir } \\
\text { suas ideias, mudando o } \\
\text { seu próprio ponto de vista } \\
\text { quando os argumentos do } \\
\text { outro são convincentes. }\end{array}$} & $\begin{array}{l}\text { 01. Ouvir as ideias dos } \\
\text { outros membros do grupo. }\end{array}$ \\
\hline & & $\begin{array}{l}\text { O2. Respeitar a opinião do outro, } \\
\text { compreendendo a importância } \\
\text { de aperfeiçoar sua forma de } \\
\text { pensar. }\end{array}$ \\
\hline & & $\begin{array}{l}\text { 03. Saber argumentar, buscando } \\
\text { a resolução de conflitos. }\end{array}$ \\
\hline & \multirow{4}{*}{$\begin{array}{l}\text { Solidariedade: Busca } \\
\text { verificar a habilidade de } \\
\text { os alunos agirem em prol } \\
\text { da união do grupo, de } \\
\text { uma associação ou da } \\
\text { sociedade. Indica que estão } \\
\text { conscientes da comunidade, } \\
\text { de seus interesses e que } \\
\text { terão sentimentos e } \\
\text { obrigações recíprocas. }\end{array}$} & $\begin{array}{l}\text { 04. Reconhecer o outro como } \\
\text { membro do grupo. }\end{array}$ \\
\hline & & $\begin{array}{l}\text { 05. Cooperar na resolução de } \\
\text { problemas. }\end{array}$ \\
\hline & & $\begin{array}{l}\text { 06. Compartilhar sentimentos e } \\
\text { conhecimentos. }\end{array}$ \\
\hline & & $\begin{array}{l}\text { 07. Habilidades para trabalhar em } \\
\text { equipe. }\end{array}$ \\
\hline \multirow{8}{*}{ Cidadania } & \multirow{2}{*}{$\begin{array}{l}\text { Diversidade: Busca verificar } \\
\text { atitudes face ao racismo, } \\
\text { à xenofobia e à orientação } \\
\text { sexual. Corresponde, } \\
\text { também, à atitude em } \\
\text { relação a doenças (AIDS, } \\
\text { Vitiligo, etc.) e deficiências } \\
\text { (mentais, auditivas, etc.) }\end{array}$} & 08. Respeitar as diferenças. \\
\hline & & $\begin{array}{l}\text { 09. Agir de maneira inclusiva, } \\
\text { facilitando a acolhida do } \\
\text { elemento novo e/ou diferente. }\end{array}$ \\
\hline & \multirow{3}{*}{$\begin{array}{l}\text { Justiça: Direitos, deveres e } \\
\text { violência. Busca verificar o } \\
\text { respeito e a obediência às } \\
\text { leis, aos direitos e deveres } \\
\text { de cada cidadão e oposição } \\
\text { à violência. }\end{array}$} & $\begin{array}{l}\text { 10. Identificar as situações de } \\
\text { violência, reconhecendo nelas } \\
\text { prejuízos para o coletivo. }\end{array}$ \\
\hline & & $\begin{array}{l}\text { 11. Compreender os princípios de } \\
\text { justiça, reconhecendo a igualdade } \\
\text { e a equidade. }\end{array}$ \\
\hline & & $\begin{array}{l}\text { 12. Agir de acordo com as leis } \\
\text { vigentes e normas/regras da } \\
\text { escola. }\end{array}$ \\
\hline & \multirow{3}{*}{$\begin{array}{l}\text { Protagonismo: É o } \\
\text { indivíduo inovador que } \\
\text { modifica, com sua forma } \\
\text { de agir, qualquer área do } \\
\text { conhecimento humano. } \\
\text { Apresenta iniciativa para } \\
\text { tomar decisões que possam } \\
\text { favorecer a si e ao coletivo. }\end{array}$} & $\begin{array}{l}\text { 13. Sentir-se responsável pelo } \\
\text { bem coletivo, comprometendo- } \\
\text { se com decisões que impliquem } \\
\text { melhoria para todos. }\end{array}$ \\
\hline & & $\begin{array}{l}\text { 14. Participar de atividades em } \\
\text { prol da coletividade. }\end{array}$ \\
\hline & & $\begin{array}{l}\text { 15. Tomar decisões que } \\
\text { beneficiem a coletividade e } \\
\text { que envolvam o seu empenho } \\
\text { pessoal. }\end{array}$ \\
\hline
\end{tabular}


A partir deste quadro foram elaborados cerca de 90 questões e/ou itens que se distribuíram por oito questionários para os alunos, sendo quatro para as crianças até o $5^{\circ}$ ano do Ensino Fundamental e quatro para os jovens do $6^{\circ}$ ano em diante, do Ensino Fundamental. Também foram elaborados dois questionários para os educadores. A montagem dos instrumentos teve o cuidado de incluir questões comuns, para que fosse possível montar uma escala na qual os três grupos (alunos até o $5^{\circ}$ ano, alunos do $6^{\circ}$ ano em diante e educadores) pudessem ser classificados. Os instrumentos apresentaram um número de itens diferentes em função da idade e escolaridade dos sujeitos e a forma de aplicação seguiu procedimentos diferentes, adequadas para cada um dos grupos.

Os itens elaborados focaram situações em que os alunos ou educadores deveriam ou poderiam se colocar para tomar decisões. Esta decisão, em alguns casos, foi apresentada em forma de múltipla escolha ou de escala de quatro intervalos em que sujeitos foram solicitados a se posicionar positiva ou negativamente.

Considerando que o projeto de avaliação teve o propósito de iniciar a construção de um instrumento de pesquisa para auxiliar no acompanhamento do programa, foi preciso elaborar uma escala para comparar o desempenho da população envolvida periodicamente, em momentos distintos. Assim, fundamentamos o trabalho de construção da escala na Teoria de Resposta ao Item (TRI) ${ }^{2}$.

A Teoria de Resposta ao Item (TRI) tem sido empregada nas avaliações de sistemas educacionais, nacionais e internacionais, como uma das alternativas para superar os limites da Teoria Clássica de Medidas (TCM).

A Teoria Clássica, amplamente utilizada nas avaliações, não permite a comparação entre indivíduos que não foram submetidos à mesma prova, uma vez que os resultados obtidos dependem do conjunto particular de itens que compõem o instrumento de medida. Nesse tipo de procedimento, as análises e interpretações estão sempre associadas a um instrumento como um todo.

O conjunto de procedimentos fundamentados na TRI apresenta uma alternativa de comparação dos resultados obtidos entre grupos pertencentes a populações diferentes, desde que submetidos a instrumentos que tenham itens comuns, ou ainda permite a comparação entre indivíduos de uma mesma população, que tenham sido submetidos a instrumentos diferentes. Isto é possível
2 Neste artigo não estaremos nos detendo nos estudos que estão sendo feitos com a TRI suas diferentes possibilidades de análise, pois ainda estamos em fase de aprofundamento dos estudos. A estatística responsável pelo estudo é Raquel da Cunha Valle, da Fundação Carlos Chagas. 
3 Características do indivíduo que não podem ser observadas diretamente como atitudes, valores, habilidades e competências. Tais características devem ser inferidas com base nas observações de variáveis secundárias que estejam relacionadas a ela.

4 Itens âncoras são itens selecionados estatisticamente. que apoiam o especialista na descrição das habilidades para cada nível da escala. porque uma das principais características da TRI é ter como elemento central os itens, e não o instrumento como um todo.

A TRI propõe modelos para avaliação dos traços latentes ${ }^{3}$, que procuram representar a relação entre a probabilidade de um aluno responder corretamente a um item e sua real habilidade e/ou competência em fazê-lo. Tal procedimento permite a criação de escalas que são definidas por meio de pontos e/ou níveis, os quais são descritos a partir da identificação dos itens âncoras ${ }^{4}$, que auxiliam na interpretação do que os alunos priorizam como valores em cada nível da escala.

Isso significa que tal procedimento possibilita a avaliação da evolução (a compreensão, o pensamento) dos alunos no que se refere aos valores ministrados pelo programa, em diferentes anos. É importante destacar que os níveis da escala são cumulativos, isto é, numa escala de 4 níveis, um aluno posicionado em um nível - por exemplo, o nível 3 - domina os valores descritos no nível em que foi classificado e o conjunto de valores descritos nos níveis anteriores (níveis 1 e 2), mas tem dificuldade para se posicionar frente aos valores que correspondem aos níveis superiores (nível 4).

Para a classificação das médias pelos intervalos das escalas das dimensões, foram elaboradas cinco escalas - uma para cada dimensão - e todas variaram de 0 a 100 pontos. Porém, os intervalos não são os mesmos, pois dependem do estudo da ordenação dos itens nas escalas. Assim, para cada uma existe um intervalo. Neste artigo não iremos nos aprofundar neste tema, mas apresentamos os pontos de corte utilizados para classificar os resultados pelos níveis da escala.

TABELA 2 - Pontos de corte dos níveis das escalas

\begin{tabular}{l|c|c|c:c:c}
\hline & $\begin{array}{c}\text { ABAIXO DO } \\
\text { NIVEL 1 }\end{array}$ & NÍVEL 1 & NÍVEL 2 & NÍVEL 3 & NÍVEL 4 \\
\hline Diálogo & Ol-15 & $15 \mid-57$ & $57 \mid-72$ & $72 \mid-87$ & $>=87$ \\
\hline Solidariedade & Ol-26 & $26 \mid-46$ & $46 \mid-66$ & $66 \mid-86$ & $>=86$ \\
\hline Diversidade & Ol-20 & $20 \mid-45$ & $45 \mid-70$ & $70 \mid-95$ & $>=95$ \\
\hline Justiça & & Ol-51 & $51 \mid-71$ & $71 \mid-91$ & $>=91$ \\
\hline Protagonismo & Ol-20 & $20 \mid-45$ & $47 \mid-62$ & $62 \mid-77$ & $>=77$ \\
\hline
\end{tabular}


A partir dos resultados do processamento de cada uma das escalas segundo a Teoria de Resposta ao Item (TRI) foi definido o nível 4 como o nível máximo de cada escala. Por outro lado, ao estudarmos a distribuição dos alunos pelos níveis, percebemos a existência de sujeitos cuja pontuação não possibilita a sua classificação no nível inicial " 1 ”. Dessa forma, criamos um nível na escala que intitulamos como "abaixo do nível 1”, mas para o qual não temos itens âncoras que permitam a descrição dos valores das pessoas que nele se classificam. A distribuição dos alunos nas escalas deverá ser feita pelos níveis assim denominados: abaixo do nível 1; nível 1; nível 2; nível 3 e nível 4.

\section{A INTERPRETAÇÃO DAS ESCALAS}

A análise dos itens âncora permitiu a descrição dos níveis das escalas, e é importante ressaltar que a descrição de cada nível depende do conteúdo do item.

Segundo o quadro 1 foram definidas 5 dimensões ou seja diálogo e solidariedade para a área referente a cooperação, e diversidade, justiça e protagonismo para a área referente a cidadania. Apresentamos neste tópico, para cada dimensão do quadro 1, a descrição dos níveis da escala a partir do conteúdo abordado nos itens âncoras, a média de cada segmento da população e a distribuição destes pelos níveis da escala. Iniciamos pela dimensão diálogo.

QUADRO 2 - Escala para a dimensão diálogo

\begin{tabular}{c|l}
\hline NIVEL & \multicolumn{1}{c}{ DESCRIÇÃo } \\
\hline 1 & $\begin{array}{l}\text { Os alunos reconhecem a importância do saber ouvir a ideia dos } \\
\text { outros em situações que não envolvem conflitos de interesse. }\end{array}$ \\
\hline 2 & $\begin{array}{l}\text { Identificam a importância de saber ouvir a ideia do outro em } \\
\text { situações que envolvem conflitos de interesse. }\end{array}$ \\
\hline 3 & $\begin{array}{l}\text { Neste nível destacam a importância em respeitar a opinião do } \\
\text { outro em situações que não envolvem conflitos de interesse. }\end{array}$ \\
\hline $\begin{array}{l}\text { Valorizam o respeito à opinião do outro em situações que } \\
\text { envolvem disputas de interesses e poder, e percebem a } \\
\text { importância do argumento como instrumento para mediar a } \\
\text { resolução de conflitos. }\end{array}$ \\
\hline
\end{tabular}


TABELA 3 - Média por segmento da população na dimensão diálogo

\begin{tabular}{l|c|c|c|c}
\hline GRUPOS & NIVEL 1 & NIVEL 2 & NÍVEL 3 & NIVEL 4 \\
\hline Crianças & & 58,4 & & \\
\hline Jovens & & 58,1 & & \\
\hline Educadores & & & 76,3 & \\
\hline Programa & & 59,1 & & \\
\hline
\end{tabular}

A partir das informações constantes da tabela 3, podemos verificar que as médias gerais alcançadas pelas crianças e jovens são de, respectivamente, 58,4 pontos e 58,1 pontos, situando-os, portanto, no nível 2 da escala de valores para a dimensão diálogo, nível esperado para ambos os grupos nessa dimensão. Os educadores apresentaram uma média de 76,3 pontos, o que os classifica no nível 3 da escala, correspondente, segundo os especialistas, ao nível esperado para esses participantes do programa.

O resultado obtido pelas crianças e jovens indica que, em média, os alunos avaliados apresentam um conjunto de valores descritos para o nível 2 da escala para a dimensão diálogo, ou seja, eles identificam a importância de saber ouvir a ideia do outro em situações que envolvem conflitos de interesse. Além disso, tais alunos dominam também os valores do nível anterior (nível 1), ou seja, reconhecem a importância do saber ouvir a ideia dos outros em situações que não envolvem conflitos de interesse.

A classificação dos educadores no nível 3 mostra que eles, além de se posicionarem positivamente em relação aos valores dos níveis anteriores, destacam a importância de respeitar a opinião do outro em situações que não envolvem conflitos de interesse.

A análise da distribuição pelos níveis da escala (Tabela 4) revela que: aproximadamente $50 \%$ das crianças apresentam uma concentração no nível 1; em proporção semelhante os jovens classificam-se no nível 2 , indicando que estes atingem, em maioria, o nível esperado para essa faixa etária. Já os professores concentram-se, na sua maioria, no nível 3 e acima dele $(72,4 \%)$. 
TABELA 4 - Distribuição percentual de cada segmento da população, pelos níveis da escala da dimensão diálogo

\begin{tabular}{l|c|c|c|c|c}
\hline \multicolumn{7}{c}{ DIMENSÃO DIÁLOGO } \\
& $\begin{array}{c}\text { ABAIXO DO } \\
\text { NÍVEL }\end{array}$ & NÍVEL 1 & NÍVEL 2 & NÍVEL 3 & NÍVEL 4 \\
\hline Crianças & 0,0 & 54,7 & 12,7 & 21,0 & 11,6 \\
\hline Jovens & 0,0 & 37,3 & 51,7 & 10,5 & 0,5 \\
\hline Educadores & 0,3 & 8,6 & 18,7 & 64,3 & 8,1 \\
\hline Programa & 0,0 & 41,5 & 37,7 & 16,4 & 4,4 \\
\hline
\end{tabular}

A análise dos itens âncoras referentes à escala solidariedade permitiu descrever os níveis da escala, segundo indicação do quadro 3.

QUADRO 3 - Escala para a dimensão solidariedade

\begin{tabular}{cll}
\hline NÍVEL & \multicolumn{1}{c}{ DESCRIÇÃo } \\
\hline 1 & $\begin{array}{l}\text { Os alunos demonstram valorizar a importância e o prazer do } \\
\text { trabalho em equipe. }\end{array}$ \\
\hline 2 & $\begin{array}{l}\text { Enfatizam que em uma equipe todos têm os mesmos direitos e } \\
\text { deveres, situação de igualdade. }\end{array}$ \\
\hline 3 & $\begin{array}{l}\text { Identificam a importância de reconhecer o outro como membro } \\
\text { do grupo, como uma forma de garantir o bom desempenho da }\end{array}$ \\
& $\begin{array}{l}\text { Identificam a importância de se ter um bom clima na equipe de tal } \\
\text { forma que se possa ter confiança para compartilhar sentimentos. }\end{array}$ \\
& $\begin{array}{l}\text { Reconhecem que o trabalho em equipe significa cooperar para a } \\
\text { resolução de conflitos. }\end{array}$
\end{tabular}

TABELA 5 - Média por população na dimensão solidariedade

\begin{tabular}{|c|c|c|c|c|}
\hline GRUPOS & NÍVEL 1 & NÍVEL 2 & NÍVEL 3 & NÍVEL 4 \\
\hline Crianças & & 58,7 & & \\
\hline Jovens & 40,5 & & & \\
\hline Educadores & & & 72,3 & \\
\hline Programa & & 47,7 & & \\
\hline
\end{tabular}

Conforme a tabela 5, a média geral alcançada pelas crianças do Programa na escala para a dimensão solidariedade é de 58,7 pontos, situando-as no nível 2 dessa escala. Os jovens 
obtiveram média de 40,5 pontos, o que os classifica no nível 1 da escala. Os educadores apresentam média de 72,3 pontos, classificando-se no nível 3 da escala, correspondente, segundo especialistas, ao nível esperado para esse grupo.

A diferença entre as médias de crianças e jovens é de 18,2 pontos. Os que os jovens estão concentrados nos níveis 1 e abaixo de 1, enquanto a concentração das crianças está nos níveis 2 e 3 , conforme pode ser mais claramente verificado na tabela 6.

O posicionamento obtido pelas crianças no nível 2 dessa escala quer dizer que, em média, esses alunos dominam o conjunto de valores descritos para esse nível, e para o nível anterior (nível 1). Ou seja, além de valorizar a ideia de que todos os membros de uma equipe têm os mesmos direitos e deveres (nível 2), eles valorizam a importância e o prazer do trabalho em equipe (nível 1). Porém, mostra que eles não conseguem identificar a importância de reconhecer o outro como membro do grupo, como uma forma de garantir o bom desempenho da equipe, nem a importância de se ter um bom clima na equipe de forma a obter confiança para compartilhar sentimentos (nível 3), como também não reconhecem que o trabalho em equipe significa cooperar para a resolução de conflitos (nível 4).

Os educadores, além de valorizar o trabalho em equipe e reconhecer a situação de igualdade entre os seus membros, identificam a importância de reconhecer o outro como membro do grupo, para garantir o bom desempenho da equipe.

TABELA 6 - Distribuição percentual de cada segmento da população, pelos níveis da escala da dimensão solidariedade

\begin{tabular}{l|c|c|c|c|c}
\hline POPULAÇÃO & $\begin{array}{c}\text { ABAIXO DO } \\
\text { NIIVEL 1 }\end{array}$ & NIVEL 1 & NÍVEL 2 & NIVEL 3 & NIVEL 4 \\
\hline Crianças & 7,3 & 19,6 & 30,4 & 28,9 & 13,8 \\
\hline Jovens & 20,6 & 40,3 & 34,0 & 4,8 & 0,3 \\
\hline Educadores & 0,0 & 5,1 & 20,5 & 42,0 & 32,4 \\
\hline Programa & 15,4 & 32,1 & 32,2 & 14,2 & 6,1 \\
\hline
\end{tabular}


A distribuição dos segmentos da população pelos níveis da escala da dimensão solidariedade revela a discrepância entre a posição das crianças e dos jovens. Observamos que 73,1\% das crianças localizam-se no nível 2 e acima dele, enquanto 60,9\% dos jovens estão classificados no nível 1 e abaixo dele. Os professores, em sua maioria, estão no nível 3 e acima dele 74,4\%.

Quanto a dimensão Diversidade seus níveis foram descritos de acordo com o quadro 4.

QUADRO 4 - Escala para a dimensão diversidade

\begin{tabular}{c|l}
\hline NIVEL & \multicolumn{1}{c}{ DESCRIÇÃO } \\
\hline 1 & $\begin{array}{l}\text { Os alunos reconhecem que existem pessoas diferentes em vários } \\
\text { aspectos e que devem ser respeitadas. }\end{array}$ \\
\hline 2 & $\begin{array}{l}\text { Identificam a importância de respeitar as pessoas que são } \\
\text { diferentes e não criticá-las, nem fazer brincadeiras de mau gosto. }\end{array}$ \\
\hline 3 & $\begin{array}{l}\text { Enfatizam a importância de não pré julgar pessoas que por algum } \\
\text { motivo se diferenciam dos demais. }\end{array}$ \\
& $\begin{array}{l}\text { Enfatizam a necessidade de dar o mesmo tratamento a todas as } \\
\text { pessoas e não marginalizá-las. } \\
\text { Reconhecem que respeitar as pessoas não implica mudar os } \\
\text { costumes de um grupo. }\end{array}$ \\
\hline
\end{tabular}

TABELA 7 - Média por população na dimensão diversidade

\begin{tabular}{|c|c|c|c|c|}
\hline GRUPOS & NÍVEL 1 & NÍVEL 2 & NÍVEL 3 & NIVEL 4 \\
\hline Crianças & & 485 & & \\
\hline Jovens & & 46,1 & & \\
\hline Educadores & & & 83,4 & \\
\hline Programa & & 48,6 & & \\
\hline
\end{tabular}

Segundo a tabela 7, as médias gerais das crianças $(48,5$ pontos) e dos jovens (46,1 pontos) os situam no nível 2 da escala de valores para a dimensão diversidade, com o Programa ocupando o mesmo nível. Os educadores, por sua vez, apresentam uma média de 83,4 pontos, quase o dobro das médias alcançadas pelas crianças e jovens, o que os classifica no nível 3 da escala para a dimensão diversidade.

Isso significa que os alunos identificam a importância de respeitar as pessoas que são diferentes, não as criticando, nem fazendo brincadeiras de mau gosto (nível 2), como 
também reconhecem que existem pessoas diferentes em vários aspectos e que devem ser respeitadas (nível 1). Porém, esse posicionamento mostra também que eles ainda não percebem a importância de não fazer julgamento prévio das pessoas que, por algum motivo, se diferenciam dos demais, nem sentem a necessidade de dar o mesmo tratamento a todas as pessoas, sem marginalizar as diferentes. Por fim, as crianças e jovens não conseguem entender que respeitar as pessoas não implica mudar os costumes de um grupo.

Já os educadores, além de considerarem importante respeitar as pessoas que são diferentes, não fazendo críticas, nem brincadeiras de mau gosto (nível 2), e reconhecerem que existem pessoas diferentes em vários aspectos que devem ser respeitadas (nível 1), enfatizam a importância de não pré julgar pessoas que por algum motivo se diferenciam das demais. No entanto, os dados da tabela 7 revelam que os educadores ainda não percebem a necessidade de dar o mesmo tratamento a todas as pessoas, a fim de não marginalizá-las, nem entendem que respeitar as pessoas não implica mudar os costumes de um grupo (nível 4).

TABELA 8 - Distribuição percentual de cada segmento da população, pelos níveis da escala da dimensão diversidade

\begin{tabular}{l|c:c|c|c|c}
\hline POPULAÇÃO & $\begin{array}{c}\text { ABAIXO DO } \\
\text { NIVEL 1 }\end{array}$ & NÍVEL 1 & NíVEL 2 & NIVEL 3 & NÍVEL 4 \\
\hline Crianças & 11,9 & 20,5 & 53,6 & 14,0 & 0,0 \\
\hline Jovens & 10,6 & 30,1 & 53,6 & 5,2 & 0,0 \\
\hline Educadores & 0,0 & 2,1 & 15,6 & 46,4 & 35,9 \\
\hline Programa & 0,0 & 25,7 & 52,1 & 10,0 & 1,7 \\
\hline
\end{tabular}

Nesta dimensão a média das crianças e jovens estão bem próximas; o mesmo ocorre com a distribuição destes pelos níveis da escala; já os professores apresentam uma concentração maior $(82,3 \%)$ nos níveis 3 e 4 que em relação às outras dimensões anteriormente vistas.

A escala de justiça elaborada a partir dos itens âncoras foi descrita segundo o quadro 5 . 
QUADRO 5 - Escala para a dimensão justiça

\begin{tabular}{c|l}
\hline NIVEL & \multicolumn{1}{c}{ DESCRIÇÃo } \\
\hline 1 & $\begin{array}{l}\text { Os alunos concordam com os princípios gerais de que devemos } \\
\text { agir de acordo com as leis e que situações de violência } \\
\text { prejudicam a todos. }\end{array}$ \\
\hline 2 & $\begin{array}{l}\text { Reconhecem de forma geral os princípios de equidade e } \\
\text { igualdade perante a lei. }\end{array}$ \\
\hline 3 & $\begin{array}{l}\text { Reconhecem que ter privilégios ou agir de forma ilegal em } \\
\text { benefício próprio é um ato que prejudica o grupo como um todo. }\end{array}$ \\
\hline 4 & $\begin{array}{l}\text { Valorizam a ideia de que um ato fora da lei é um crime e passível } \\
\text { de punição. } \\
\text { Percebem que se deve agir de acordo com a lei, não se podendo } \\
\text { colocar acima dela. }\end{array}$ \\
\hline
\end{tabular}

TABELA 9 - Média por população na dimensão justiça

\begin{tabular}{l|c:c:c:c}
\hline GRUPOS & NIVEL 1 & NIVEL 2 & NIVEL 3 & NIVEL 4 \\
\hline Crianças & 33,6 & & & \\
\hline Jovens & 30,6 & & & \\
\hline Educadores & & & 74,5 & \\
\hline Programa & 33,6 & & & \\
\hline
\end{tabular}

Como se verifica na tabela 9, as médias alcançadas pelas crianças (33,6 pontos), jovens (30,6 pontos) e programa como um todo (33,6 pontos) na escala para a dimensão justiça, situam-se no nível 1 e mostram que esses grupos se apropriaram apenas dos valores mais gerais e abstratos de justiça. Os educadores têm média de 74,5 pontos, que os posiciona no nível 3 da escala para a dimensão justiça.

Os dados da tabela 9 revelam que crianças e jovens não atingiram o nível 2 na escala esperado para ambos os grupos na dimensão justiça. Isso quer dizer que tanto as crianças como os jovens estão apenas de acordo com os princípios gerais de que devemos agir conforme as leis e que situações de violência prejudicam a todos. Isso provavelmente acontece porque a violência está no dia a dia de todos nós, e esses alunos têm condições concretas de senti-las como algo negativo na sua vida.

Em relação à dimensão justiça, eles ainda não são capazes de reconhecer mesmo de forma geral os princípios de equidade e igualdade perante a lei (nível 2), nem perceber que ter 
privilégios ou agir de forma ilegal em benefício próprio é um ato que prejudica o grupo como um todo (nível 3). As crianças e jovens também não conseguem dar valor à ideia de que um ato fora da lei é um crime e passível de punição, assim como não entendem que é preciso agir de acordo com a lei, não podendo se colocar acima dela (nível 4). Estes dados por terem sido inesperados serão passíveis de estudos posteriores.

Já os educadores, em média, demonstram concordar com os princípios gerais de que devemos agir de acordo com as leis e que situações de violência prejudicam a todos (nível 1), reconhecem de forma geral os princípios de equidade e igualdade perante a lei (nível 2), e também que ter privilégios ou agir de forma ilegal em benefício próprio é um ato que prejudica o grupo como um todo (nível 3).

No entanto, eles ainda não valorizam a ideia de que um ato fora da lei é um crime e passível de punição, nem percebem que sua ação precisa estar de acordo com a lei, não podendo se colocar acima dela (nível 4).

TABELA 10 - Distribuição percentual de cada segmento da população, pelos níveis da escala da dimensão justiça

\begin{tabular}{l|c:c|r:r|r}
\hline POPULAÇÃO & $\begin{array}{c}\text { ABAIXO DO } \\
\text { NIVEL 1 }\end{array}$ & NÍVEL 1 & NÍVEL 2 & NÍVEL 3 & NÍVEL 4 \\
\hline Crianças & 0,0 & 90,3 & 9,7 & 0,0 & 0,0 \\
\hline Jovens & 0,0 & 97,4 & 2,6 & 0,0 & 0,0 \\
\hline Educadores & 0,0 & 11,8 & 25,9 & 39,3 & 23,0 \\
\hline Programa & 0,0 & 91,1 & 6,0 & 1,8 & 1,1 \\
\hline
\end{tabular}

É na dimensão justiça que observamos as classificações mais baixas, $90 \%$ das crianças e dos jovens se classificam no nível 1; não observamos nenhum deles classificados nos níveis 3 e 4 . Apenas $62,3 \%$ dos professores se classificam entre os níveis 3 e 4.

A descrição dos níveis de protagonismo estão descritas no quadro 6. 
QUADRO 6 - Escala para a dimensão protagonismo

\begin{tabular}{c|l}
\hline NÍVEL & \multicolumn{1}{c}{ DESCRIÇÃO } \\
\hline 1 & $\begin{array}{l}\text { Os alunos valorizam atitudes em que as pessoas se sintam } \\
\text { responsáveis pelo ambiente em que vivem. }\end{array}$ \\
\hline 2 & $\begin{array}{l}\text { Valorizam situações em que as pessoas tomem iniciativas (se } \\
\text { empenhem pessoalmente) para melhorar a condição do meio em } \\
\text { que vivem. }\end{array}$ \\
& $\begin{array}{l}\text { Valorizam atitudes em que as pessoas se mobilizem para dar } \\
\text { solução a problemas que afetem a sociedade como um todo. }\end{array}$ \\
\hline 4 & $\begin{array}{l}\text { Percebem-se como membro de uma comunidade responsável } \\
\text { pelo bem-estar da mesma. } \\
\text { Buscam soluções alternativas para não prejudicar o ambiente em } \\
\text { que vivem. }\end{array}$
\end{tabular}

TABELA 11 - Média por população na dimensão protagonismo

\begin{tabular}{l|c|c|c|c}
\hline GRUPOS & NIVEL 1 & NIVEL 2 & NIVEL 3 & NIVEL 4 \\
\hline Crianças & 40,5 & & & \\
\hline Jovens & & 47,7 & & \\
\hline Educadores & & & & 88,4 \\
\hline Programa & & 47,3 & & \\
\hline
\end{tabular}

Ao contrário da dimensão solidariedade, a média das crianças $(40,5)$ em protagonismo se posiciona no nível 1 da escala e a dos os jovens $(47,7)$ no nível 2. Este resultado indica que as crianças são mais solidárias e menos empreendedoras (no sentido de agir por si mesmas) e os jovens mais empreendedores e menos solidários, coisa que pode ser própria da idade em que se encontram. Em relação à escala referente a essa dimensão, os educadores têm sua média situada no nível 4 (88,4 pontos). Isso quer dizer que eles se encontram em um nível superior ao que é esperado para esse grupo e superior às escalas anteriores.

A posição das médias dos alunos indica que os jovens valorizam atitudes e situações em que as pessoas tomam iniciativas (se empenham pessoalmente) para melhorar a condição do meio em que vivem (nível 2), e atitudes em que as pessoas se sentem responsáveis pelo ambiente em que vivem (nível 1). No entanto, ainda não conseguem dar valor às atitudes em que as pessoas se mobilizam para dar solução a problemas que afetam a sociedade como um todo (nível 3), nem se percebem como 
membro de uma comunidade responsável pelo bem-estar geral, não sendo capazes, portanto, de buscar soluções alternativas para não prejudicar o ambiente em que vivem (nível 4).

Já os educadores, com média situada no nível 4 da escala para protagonismo, se sentem responsáveis por decisões, iniciativas e atividades importantes para o seu ambiente pessoal e na sociedade, o que os leva a buscar soluções alternativas para não prejudicar o ambiente em que vivem.

Além desses valores, os educadores valorizam as atitudes nas quais as pessoas se sentem responsáveis pelo ambiente em que vivem (nível 1), as situações em que as pessoas tomam iniciativas (se empenhem pessoalmente) para melhorar a condição do meio em que vivem (nível 2) e as atitudes em que as pessoas se mobilizam para dar solução a problemas que afetam a sociedade como um todo (nível 3).

TABELA 12 - Distribuição percentual de cada segmento da população, pelos níveis da escala da dimensão protagonismo

\begin{tabular}{l|c|c|c|c|c}
\hline POPULAÇÃO & $\begin{array}{c}\text { ABAIXO DO } \\
\text { NIVEL 1 }\end{array}$ & NIVEL 1 & NíVEL 2 & NIVEL 3 & NÍVEL 4 \\
\hline Crianças & 11,9 & 47,6 & 37,6 & 2,9 & 0 \\
\hline Jovens & 5,4 & 46,4 & 23,1 & 24,4 & 0,7 \\
\hline Educadores & 1,4 & 3,6 & 3,0 & 7,7 & 84,3 \\
\hline Programa & & 44,8 & 26,8 & 16,8 & 4,3 \\
\hline
\end{tabular}

Existe entre as crianças e os jovens uma diferença em relação ao nível 3 que permite classificar a média dos jovens em um nível maior que os das crianças; porém, devemos ressaltar que aproximadamente metade dos sujeitos investigados em ambas populações encontram-se nos níveis 1 e abaixo dele. Os professores, talvez pela natureza de sua profissão, encontram-se concentrados no nível 4.

\section{COMENTÁRIOS FINAIS}

A construção de uma escala de valores com a metodologia da Teoria de Resposta tem a ver com avaliações (quantitativas) em larga escala. O propósito é oferecer aos educadores em curto prazo uma visão geral dos valores e da forma de pensar de seus 
alunos e, em longo prazo (acompanhamento longitudinal), desvelar as oscilações de comportamentos em termos de valores ou suas distorções. A função da escala é instrumentalizar professores na elaboração de linhas de ação sobre os pontos mais críticos. Neste sentido não foi oferecido uma escala geral, mas cinco escalas, uma para cada dimensão descrita na matriz.

Ao repassarmos os resultados aos educadores, foi possível perceber, na apresentação da matriz, a importância da existência de indicadores que possam orientar o trabalho dos docentes e como a descrição das escalas pode aclarar pontos de orientação para o planejamento de trabalho no dia-a-dia da sala de aula.

Esse é o primeiro passo dado na proposta de construção de uma escala e teve uma perspectiva de estudo piloto. A partir daí, esperamos dar continuidade aos estudos, procurando aprimorar a escala nos seguintes aspectos: revisão da matriz elaborada, ampliação dos descritores e elaboração de novos itens, tendo em vista o processo inicial. A experiência revelou, na dimensão justiça, que descritores relacionados ao tópico ficaram em sua maioria focados em uma postura legalista, vinculada aos direitos e deveres do cidadão, o que pode ter provocado o baixo posicionamento das crianças e jovens na escala.

Finalmente, é necessário ressaltar que avaliações em larga escala podem se constituir em instrumento indicativo para o desenvolvimento humano dos habitantes de uma cidade, no que tange ao convívio social, permitindo refinar o olhar, ao observar diferentes aspectos da dimensão valores, no amplo leque de iniciativas educadoras que vemos surgir no campo educacional, englobando instituições formais (escolas) e intervenções não formais (ONGs), como aponta a Declaração de Barcelona, conhecida como Carta das Cidades Educadoras.

\section{REFERÊNCIAS BIBLIOGRÁFICAS}

DEL PRETTE, Zilda A.P.; DEL PRETTE Almir. Psicologia das habilidades sociais na infância: teoria e prática. Petrópolis: Vozes, 2009. 
FUNDAÇÃO SICREDI: Conhecendo o Programa “A União Faz A Vida”. Porto Alegre: Fundação Sicredi, 2008.

GIL RODRIGUEZ, Francisco; LEÓN RUBIO, José Maria. Habilidades Sociais Teoria, investigación e intervención. Madrid: Síntesis, 1998.

LA TAILLE, Yves; MENIN, Maria Suzana De Stefano. Crise de valores ou valores em crise? Porto Alegre: Artmed, 2009.

MACHADO, Joaquim. Cidade educadora e administração local da educação na cidade de Braga. In: CONGRESSO PORTUGUÊS DE SOCIOLOGIA, 5., Braga. Actas... Sociedades contemporâneas: reflexividade e acção. Atelier: Cidades, campos e territórios. Braga: Universidade do Minho, de 12 a 15 de maio de 2004 .

SUMMERS, Gene F. Medición de Actitudes. México: Trillas, 1976.

VALLE, Raquel da Cunha. Teoria de Resposta ao Item. 1999. Dissertação (Mestrado) - Instituto de Matemática e Estatística, Universidade de São Paulo, São Paulo, 1999.

\section{MARIALVA ROSSI TAVARES}

Pesquisadora do Núcleo de Estudos em Avaliação (NEA) da Fundação Carlos Chagas

mtavares@fcc.org.br 